\title{
Family Health Exercise: Follow-up of an Extra-pulmonary Tuberculosis Patient
}

\author{
Thapa K*, Sharma D, Karki D, Sharma D, Gurung FK, Tanwar J, Pariyar L \\ MBBS $4^{\text {th }}$ year (2012 batch), Gandaki Medical College \& Teaching Hospital, Pokhara, Nepal, *Group Leader
}

\author{
Keywords \\ Family health exercise, Mycobacterium \\ tuberculosis, Tuberculosis.

\section{Corresponding author \\ Mr. Kavindra Thapa \\ MBBS 4th year (2012 batch) \\ Gandaki Medical College \& Teaching \\ Hospital, Pokhara, Nepal \\ Email: thapakavindra@gmail.com}

\begin{abstract}
During the third year of MBBS program, we had a course of family health exercise in community medicine. This course was designed to produce competent family physicians; to enable us to understand the social, cultural, psychological, gender and economical aspects of illness, the interactions of ill persons with different members of the family and community health service, role of family members and family environment in patient care. It helped us to understand the natural history of the disease and importance of patient follow up. We were able to differentiate the nature of the problems while seeing the patients in the family from the nature of the same problems when the patient is seen in clinic or hospital. Here we present a follow-up of extra-pulmonary tuberculosis patient in our family health exercise during third year

MBBS program.
\end{abstract}

\section{INTRODUCTION}

Tuberculosis (TB) is a chronic infectious disease which is remained as public health problem in Nepal. Tuberculosis is mostly caused by Mycobacterium tuberculosis. It mostly affects the lungs (pulmonary tuberculosis) and intestines, bones, joints, bone marrow, bone, liver, urinary bladder and almost all organs of the body (extra pulmonary tuberculosis). Due to the co-morbid with HIV it has become a global problem. TB is not only a public health problem it is also a social and economic problem.

\section{CLINICAL FEATURES OF TUBERCULOSIS}

- Cough for $>3$ weeks

- Sputum production

- Weight loss

- Night sweating

- Loss of appetite

- Low grade fever

- Hemoptysis

However, manifestations may differ according to organs affected.

\section{PROBLEM BURDEN}

- Mycobacterium tuberculosis infects one third of world's population.

- Globally 1.7 to 2 billion people are infected with tubercle bacilli.

- About 8 million people develop active TB disease every year.

- About 1.3 million people die every year.

- Asia (SEAR and Western Pacific region) accounts for $55 \%$ of the global TB cases.

\section{STATUS IN NEPAL}

According to annual report 2014/15 A.D. (2070/71 B.S.), about $45 \%$ of the total population is affected with the TB of which $60 \%$ are adults. Every year 45,000 people develop active TB, out of which 20,500 develop infectious pulmonary disease. Treatment by DOTS has reduced the number of the deaths however 5,000-7,000 people are still dying per year by TB despite of the DOTS implementation. 
Epidemiological Determinants

\section{A. Agent Factors}

a. Agent:

- Mycobacterium tuberculosis, also M. bovis, M. avium, M. microti and M. africanum.

- An acid fast bacilli, non-motile, non-spore forming and non-capsulated, arranged singly or in groups.

\section{b. Source of infection:}

There are two source of infection

- Human source: Most common is the human case whose sputum is positive for tubercle bacilli and cases who has either received no treatment or has not been fully treated.

- Bovine source: Infection from infected milk (zoonotic).

\section{c. Communicability:}

- Patients are infective as long as they remain untreated.

- Effective antimicrobial treatment reduces infectivity by $90 \%$ within 48 hours and non-infective in 15 days.

\section{B. Host Factors}

a. Age: Affects all ages; developing countries show a sharp rise in infection rates from infancy to adolescence and extreme ages.

b. Sex: More common in males than in females.

c. Nutrition: Malnutrition one of the major cause as it predisposes to TB.

d. Immunity: No inherited immunity against TB infection. Immunity acquired as a result of natural infection or BCG vaccination.

Percentage of children under one year immunized with BCG was 99\% (according to annual report 2014/15 A.D. (2070/071 B.S.).

\section{Environmental Factors}

a. Poor quality of life, low socio economic status, poor housing, over crowding

b. Under nutrition

c. Lack of education

d. Lack of awareness of causes of illness

e. Occupation: People with pneumoconiosis especially silicoses are more prone to TB and also common in medical professionals. Tuberculosis thrives in condition of poverty and can worsen poverty.

\section{Incubation Period}

It may be weeks, months or years. It takes three to six weeks for the development of positive tuberculin test after infection.
Mode of Transmission: Droplet infection and droplet nuclei.

\section{SELECTION OF THE CASE/ CASE STUDY}

As TB is a public health problem in Nepal, it not only affects the health of the person but its surrounding contacts and also affects in economy and social aspects of people. We explained about our family health program and requested for the support. They agreed to help us. As we are going through the files in OPD for the selection of case, we came to know this case that could fit in the category of Infectious disease. We collected the information about the patient from duty staff, contacted her family.

\section{CASE HISTORY}

Patient's profile

Name: Maya Bhusal [name changed]

Age: 58 years

Sex: Female

Marital Status: Married

Religion: Hindu

Occupation: Housewife

Address: Nagdhunga, Pokhara

Date of Diagnosis: $13^{\text {th }}$ January, 2016 A.D. (2072/09/29 B.S.)

\section{Chief complain}

- Lesions over the right seventh inter-costal space for six days.

- $\quad$ Fever for three days.

\section{History of present illness}

According to the patient she was apparently well eight days back. Then she developed a lesion over the right seventh inter-costal space. The lesion was red over its margin and she felt pain all the time and while touching, the pain increases. Then she developed fever which was intermittent with chills and sweating especially at the evening. Also she developed vomiting two to three times a day which was non-projectile, non-billous, food contents and no blood in vomitus. Then she developed diarrhea two to three times a day but no blood present in diarrhea. Then she was admitted to Gandaki Medical College and Teaching Hospital. While she was under-treatment she developed cough with sputum mucopurulent and no blood stain in cough also she had difficulty in coughing out.

\section{Past history}

There was the history of uterus infection due to which she had to undergo hysterectomy in January 2015 A.D. (Magh, 2071 BS). Then after she had body swelling with non-projectile cough and sputum production, which 
increased in night and difficulty in breathing, vomiting and fever after body swelling decreased in April, 2015 A.D. (Baishak, 2072 B.S.).

\section{Personal history}

She is non-smoker, non-alcoholic and non-vegetarian.

Presence of BCG scars on left deltoid region.

\section{Allergy history}

No known allergy to any drug.

\section{Surgical history}

Hysterectomy

\section{Family history}

There is no history of tuberculosis, diabetes, hypertension and epilepsy in the family.

\section{Socio-economic history}

She belongs to middle class family.

\section{PHYSICAL EXAMINATION}

\section{General condition}

- Patient was ill looking, conscious and well oriented to the time, place and person and cooperative.

- Weight: $38 \mathrm{~kg}$

\section{Vitals}

- Pulse: $86 / \mathrm{min}$.

- $\quad$ B.P.: $160 / 90 \mathrm{mmHg}$

- Temperature: $100.4^{\circ} \mathrm{F}$

- Respiratory rate: 16 breaths/min

\section{General condition}

- Pallor - present

- Icterus - absent

- Clubbing - absent

- Cyanosis - absent

- Lymphadenopathy - absent

- Edema - absent

- Dehydration - absent

\section{Systemic Examination}

\section{Respiratory system}

- Bilateral clear bronchial breath sound and no wheeze or added sound.

\section{Cardiovascular system}

- Normal first and second heart sounds. No added heart sound.

\section{Per abdomen}

Inspection:

- Scaphoid shape
- Skin seems to be dark n pale in color

- Umbilicus is inverted, centrally located and spherical in shape.

- No any scars mark.

- No venous engorgement

\section{Palpation:}

- Superficial: No local rise of temperature.

- Deep: No tender on palpation.

\section{Percussion:}

- Tympanic sound heard over the abdominal surface and dull over liver area.

\section{Auscultation}

- Normal bowel sound and absence of bruits.

- Bowel sounds present two per minute.

\section{INVESTIGATIONS}

1. Complete blood count.

- $\mathrm{Hb}: 12.4 \mathrm{gm} \%$

- WBC: $9400 / \mathrm{mm}$

- Neutrophils: $67 \%$

- Lymphocytes: $30 \%$

- Monocytes: 00\%

- Eosinophils: 03\%

- ESR: $94 \mathrm{~mm}$ in first hour

- Platelets: 320,000/ $\mathrm{mm}^{3}$

2. Sugar: Random 93 mg/dl

3. Chest x-ray: Normal

5. USG abdomen: Normal USG scan.

\section{Diagnosis}

Extra-pulmonary TB (Granulomatus with chronic suppurative mastistis)

Treatment

\begin{tabular}{lll}
\hline Medication & Dose & Duration \\
\hline Isoniazide & $75 \mathrm{mg}$ & 2 months + 4 months \\
Rifampicin & $150 \mathrm{mg}$ & 2 months + 4 months \\
Pyrazinamide & $400 \mathrm{mg}$ & 2 months \\
Ethambutol & $275 \mathrm{mg}$ & 2 months \\
\hline
\end{tabular}

\section{FAMILY VISIT}

First visit $24^{\text {th }}$, June, 2014 A.D. (2072/09/03 B.S):

Objectives:

- To locate the house, introduce ourselves and rapport building

- To explain them about the purpose of our visit

- To perform key informant interview and/or in-depth interview with head of household 
- To explore the family background

- To collect data on physical facilities, socioeconomic environment around the house through observation checklist

- To collect data on compliance of treatment and progress of health status

\section{Activities:}

After all necessary arrangements, we headed towards Nagdhunga which about 10 minutes from our living area. We requested Mrs. Bhusal's daughter to receive us at the main road. After walking for five minutes leaving the small road, we reached a double storeyed house. The home was their own. Due to the patient's request we sat comfortably inside the living room. We observed the surrounding environment and after objectives of our first visit were met, we left reminding her to go to DOTS centre and take medicine and assuring her to visit again next week.

\section{Outcomes:}

\section{- Family profile}

\begin{tabular}{llccc}
\hline $\begin{array}{c}\text { S } \\
\text { No }\end{array}$ & $\begin{array}{c}\text { Relation with } \\
\text { patient }\end{array}$ & Age & $\begin{array}{c}\text { Educa- } \\
\text { tion }\end{array}$ & Occupation \\
\hline 1. & Husband & 60 & Grade 7 & $\begin{array}{c}\text { Retired In- } \\
\text { dian army } \\
\text { 2. }\end{array}$ Son \\
3. & Daughter-in-law & 27 & Bachelor & Abroad \\
4. & Daughter & 30 & SLC & Housewife \\
5. & Daughter & 28 & Bachelor & Housewife \\
6. & Son & 26 & +2 & Abroad \\
7. & Daughter-in-law & 24 & Bachelor & Housewife \\
8. & Son & 24 & +2 & Student \\
9. & Granddaughter & 10 & Grade-5 & Student \\
10. & Grandson & 8 & Grade-2 & Student \\
11. & Grandson & 6 & - & \\
& & months & & \\
\hline
\end{tabular}

\section{Socioeconomic Status}

The patient belongs to the upper middle class family (score-18) according to Kuppuswamy's socio-economic status scale. The main source of income for the family was the rent of the house and agriculture. Since the incident four days ago he hasn't gone to the workplace and his wife is busy taking care of him so the shop is also closed for four days.

\section{Observation checklist}

\section{Housing}

- Type of house: Pakka

- House: rent
- $\quad$ Rent per month: Rs 8000

- No of rooms: one per person

- No of windows per room: three per room

- Lighting: satisfactory

- Cross Ventilation: No

- Kitchen (separated): Smokeless

- Source of fuel: LPG and wood

\section{Assets:}

- Television: one

- Refrigerator: one

- Mobile: four sets

- Cooking appliances: Rice cooker, pressure cooker

- Furniture: Bed, cupboard

\section{Sanitation:}

- Toilet: one

- Type: Watershield

- Distance from water source: 20 meters

- Odor: pleasant

- Flies : Absent

- Mode of disposal of household wastes

- Decomposable: Municipality vehicle

- Non-decomposable: Municipality vehicle

- Kitchen: Clean

- Source of water: Clean

- Cattle shed: Absent

- Ditches around house: Absent

Second visit $25^{\text {th }}$ December, 2015 A.D. $(2072 / 09 / 10$ B.S.):

Objectives:

- To know about the disease progression and compliance of the patient on disease

- To evaluate the role of family in disease and impact in family

- To know about the health seeking behavior and knowledge, attitude and practice (KAP) of disease on the family and the consequent changes in their KAP regarding this

- To evaluate the gender role through the gender analysis

\section{Activities}

We went for second visit 10 days later. This time we were with our supervisor. We were focused in asking about disease progression as well as improvement of the patient and the effects of disease on the patient, her family and the society and the role of family in the disease causation, progression and recovery of disease. We also asked about health seeking behavior, KAP and belief system and the 
coping strategies of family members. We found that the patient was taking his medications in time and was showing signs of improvement.

\section{Outcomes:}

\section{Compliance of patient with the disease:}

The patient is taking her daily medications from the nearby DOTS centre. She also consumes a proper diet, as she was advised by his doctor. Also she goes on daily dressing of the abscess. She felt that she is improving and want to take food than before.

\section{Effects of family in the disease:}

\section{Role in causation}

Since Mrs. Bhusal lives with her family, her daughter and daughter-in-law cook foods and take care of her.

\section{Role in progression and relief:}

Her family seems to be worry after her suffering. Family members supported her and took care so much that she was satisfied by her family. Her husband or daughter or daughter-in-law used to take her to hospital and other check up. Her family also encouraged her to take healthy nutrition.

\section{Effects of the Disease \\ In the patient}

The disease has limited the patient from her daily household work which she used to do. Also she seems to be conscious about her health so she regularly attend the DOTS centre

\section{In the family}

A considerable amount of money has been spent on her treatment for medication. The total expenditure till now was around Rs 6,00,000/. According to patient, the regular follow and check up needs a lot of money, but it has become difficult to arrange money sometimes.

\section{Knowledge, attitude and practice on disease:}

Mrs. Bhusal knew that it would be harmful to her if she did not take the medicine but she did not know about the progression of the disease. Whenever anyone in the family becomes ill they first go to hospital however, they still believe in traditional healing side by side.

\section{Tools for gender analysis:}

It seems they have both adapted to their modern life style. Both Mrs. Bhusal and her husband seem to do the household chores of cooking, cleaning and maintaining the house together. Mr. and Mrs. Bhusal, both are the bread winners.

\begin{tabular}{|c|c|c|c|}
\hline Activities & $\begin{array}{l}\text { Women/ } \\
\text { girls }\end{array}$ & $\begin{array}{l}\text { Men/ } \\
\text { boys }\end{array}$ & Both \\
\hline Breadwinner & & & ++ \\
\hline Source of income & & ++ & \\
\hline Agriculture & ++ & & \\
\hline Business & & ++ & \\
\hline Jobs & & ++ & \\
\hline Budget allocation & & ++ & \\
\hline Household chores & & & ++ \\
\hline Cooking & ++ & & \\
\hline Water related & & & ++ \\
\hline Water collection & & & ++ \\
\hline Water dishes & ++ & & \\
\hline Cleaning dishes & ++ & & \\
\hline Marketing & & & ++ \\
\hline Health related activities & & & ++ \\
\hline Decision of the health care & & & ++ \\
\hline Care during illness & & & ++ \\
\hline $\begin{array}{l}\text { Taking sick to health care } \\
\text { centre }\end{array}$ & & & ++ \\
\hline Care during illness & & & ++ \\
\hline $\begin{array}{l}\text { Taking sick to health care } \\
\text { centre }\end{array}$ & & & ++ \\
\hline Purchasing medicine & & & ++ \\
\hline Immunization of the child & & & ++ \\
\hline Family planning & & & ++ \\
\hline Child care & ++ & & \\
\hline Maintainence tasks & & & ++ \\
\hline
\end{tabular}

\section{Access and control profile}

\begin{tabular}{lcccc}
\hline Particulars & $\begin{array}{c}\text { Access } \\
\text { Women/ } \\
\text { girls }\end{array}$ & $\begin{array}{c}\text { Men/ } \\
\text { boys }\end{array}$ & $\begin{array}{c}\text { Control } \\
\text { Women/ } \\
\text { girls }\end{array}$ & Men/boys \\
Resources & ++ & & ++ \\
Assets & & ++ & \\
Cash & ++ & & ++ & \\
Education & & ++ & ++ & \\
Basic needs & & ++ & ++ \\
Food & & ++ & ++ \\
Shelter & & ++ & \\
Clothing & & ++ & ++ & ++ \\
\hline
\end{tabular}

Access and control profile shows a difference of zero, which is less than five, so the gender situation is good. 
Third visit $31^{\text {st }}$ January, 2016 A.D. (2072/09/17 B.S.): Objectives

- To know about the progress of the disease over the period of time

- To counsel the patient and family members and encourage them for change, if necessary

- To measure the effects of the second visit

\section{Activities}

On our last visit we talked to the patient and her husband and family to assess what they absorbed from the last counseling we did on the second visit. It turns out that the patient has been willing to follow the advices given by the doctor and as well as us. We also asked any missing questions, after reviewing our notes of the family. We left the Mr. and Mrs. Bhusal on great terms and even exchanged numbers, just in case she may have any questions for us in the future.

\section{Outcomes:}

\section{Counseling the family}

We counseled Mrs. Bhusal about following the advice given to him by her doctor. Also, how important it is to take her medications in a timely manner, eating a proper diet, and exercising to cure and be TB free. We also emphasized that if she maintained these factors, she need not worry about future complications of the disease.

\section{Conclusions}

Tuberculosis is caused by Mycobacterium tuberculosis and its resistance is increasing day by day. Proper DOTS treatment and complete treatment is necessary in order to reduce the complications, resistance and relapse cases in future.

\section{REFERENCES}

1. K. Park. Park's Textbook of Preventive and Social Medicine, 23rd Edition. 2015. Banarsidas publishers, Jabalpur (MP), India.

2. AH Suryakantha. Community medicine with recent advances. Third edition. Jaypee. 2014.

3. Mahajan \& Gupta. Text book of preventive and social medicine. Revised by Rabindra Nath Roy, Indranil Saha. Fourth edition. 2013. Jaypee.

4. Sunder Lal, Adarsh, Pankaj. Text book of community medicine. Preventive and social medicine. CBS publishers. 2011.

5. Lalita D. Hiremath, Dhananjaya A. Hiremath. Essentials of community medicine: A practical approach. Jaypee. 2010.

6. Drug-resistant tuberculosis management guidelines and manual. Government of Nepal. Ministry of Health and Population, National Tuberculosis Control Programme. November 2011. 